\title{
The trends of hourly carbon emission factors in Germany and investigation on relevant consumption patterns for its application
}

\author{
Jun Kono $^{1}$ (D) $\cdot$ York Ostermeyer $^{1} \cdot$ Holger Wallbaum ${ }^{1}$
}

Received: 11 May 2016/Accepted: 31 January 2017 /Published online: 13 February 2017

(C) The Author(s) 2017. This article is published with open access at Springerlink.com

\begin{abstract}
Purpose The share of variable renewable energy sources (vRES) in the German electricity grid has increased over the past few decades. Due to the nature of the generation pattern of vRES, the increase of vRES causes the emission factor (EF) to fluctuate on an hourly basis. This fluctuation raises concerns about the accuracy of quantifying emissions with the current metric of the annual average EF as the respective EF may change depending on the time at which it is consumed. Methods The study calculated the hourly EF of Germany from 2011 to 2015 and investigated the effect of an increase of vRES on the EF. The calculated hourly EF was clustered based on three aspects of time: the period of time, the time of a day, and the day of the week.

Results and discussion The study showed a higher proportion of vRES on weekend daytimes while the weekday nighttimes resulted in a lower share than the annual average. The study highlighted potential underestimation and overestimation of emissions by using annual average EF which ranged from $+22 \%$ (2015 weekday nighttime of October) to $-34 \%$ (2015 weekend daytime of May).

Conclusions The study suggested that the application of hourly EF may be necessary to quantify the respective emission from the consumers that use electricity during the weekend daytime and weekend nighttime. For consumer use at other times, the emissions could be quantified appropriately by using the conventional annual average $\mathrm{EF}$.
\end{abstract}

Responsible editor: Rolf Frischknecht

Jun Kono

jun.kono@chalmers.se

1 Department of Civil and Environmental Engineering, Chalmers University of Technology, 41296 Gothenburg, Sweden
Keywords Climate change $\cdot$ Consumption pattern · Dynamic LCI $\cdot$ Emission factor $\cdot$ Environment

\section{Introduction}

Electricity is one of the key inventories in a life cycle assessment (LCA); it is frequently used to describe the life cycle inventory (LCI) of various products (Mendoza et al. 2012; Torrellas et al. 2012; Treyer and Bauer 2016). The prevalence of the electricity inventory's use in LCA studies suggests that the accuracy of the inventory may significantly impact the result of an LCA. There exists a tremendous variety of electricity inventories in ecoinvent, with 71 geographical regions being represented (Weidema et al. 2013). Currently, the inventory of electricity is based on the annual share of energy sources in the electricity grid mix of a country. Based on this mix, the annual average carbon emission factor $(\mathrm{EF})$ of electricity is calculated and used to quantify the emission from consumed electricity.

However, the electricity mix has changed rapidly over the last few decades in response to the emission reduction goals set by many countries to combat climate change. For example, the EU set the emission reduction target of $20 \%$ by 2020 through the Climate and Energy Package (Commission of the European Communities 2008). In keeping with the commitments outlined, the share of renewable energy sources in the electricity grids increased in several countries. Germany is one of the countries that has successfully increased their share of renewables in the grid. As a result, the grid mix of Germany has transformed over the previous few decades.

The share of renewable energy increased from 3\% in 1990 to 30\% in 2015 (BDEW 2016; BMU 2013; Morris and Pehnt 2015). In other words, the share of renewable energy in the German electricity grid increased tenfold in 25 years (BDEW 
2016; BMU 2013). Within the increased share of overall renewable energy, the contribution of variable renewable energy sources (vRES), such as solar and wind, was significant. The electricity generation from vRES is dependent on the time when the energy sources are available, which restricts the ability to plan electricity generation in the same manner as is possible with conventional power plants. As a consequence of the increased share of such renewables in the grid, a variation of the electricity grid mix could be expected depending on the time of day. In fact, the study by Paraschiv et al. (2014) offers that the renewable energies in the electricity spot market enhances the deviation in price in Germany.

With the energy mix varying with increased vRES, the corresponding carbon emission by consuming $1 \mathrm{kWh}$ of electricity may change depending on the time. This indicates the weakness of the current usage of annual average EF for quantifying emission from electricity consumption, depending on when the electricity is consumed. Indeed, previous studies state the lack of temporal information in LCA as an important limitation of LCA (Levasseur et al. 2010; Pinsonnault et al. 2014; Reap et al. 2008). To better quantify the respective emission for a specific consumer, higher resolutions of EFs may become relevant. Moreover, with the increase of vRES in Germany as well as various European countries such as Denmark, Italy, and Spain (Eurostat 2016), the importance of yielding a higher resolution of EF of electricity may become relevant for other countries as well. With the adoption of the Paris Agreement in COP21 (UNFCCC 2016), the uptrend in share of vRES can likely be expected in other nations and continents as well.

Recent studies have generated a higher resolution of carbon EFs of electricity for Belgium (Messagie et al. 2014) and Canada (Cubi et al. 2015). However, the German grid system is somewhat unique in its sizeable share of vRES and the size of the power market, which renders the country an interesting case study for assessing the effect of the higher resolution on EF on quantifying carbon emissions. Therefore, this study calculated an hourly resolution of the carbon EF of the German electricity grid mix to assess the relevance of the time of day when the electricity is consumed. To quantify the EF, a life cycle impact assessment (LCIA) was made for each power source. The hourly EF of 5 years (2011-2015) was clustered in various time resolutions based on the period of time, the day of the week, and the time of day. With the clustering, the study intended to highlight that the use of hourly EF grows in significance depending on the consumption patterns of a consumer.

\section{Methods}

The hourly electricity generation data for Germany was used to calculate the hourly EFs. Based on the energy mix of the generation data, the hourly EF was calculated. The following section introduces the source and method for calculating the averaged EFs.

\subsection{Data sources for generation}

The hourly electricity generation data for the German electricity grid was sourced from the EEX (European Energy Exchange AG 2015). The data represents the net electricity generation of a specific hour from companies participating in the wholesale electricity market of EEX. In Table 1, the German national statistics of the gross electricity generation and the share of generation data covered by the study are depicted. Due partly to the fact that not all electricity generation facilities are represented in the EEX market, and partly to the differing representations of generation data, the data in the study represented about $65 \%$ of the gross German electricity generation (BDEW 2016). For the studied years, the representation of the electricity generated from renewables covered in the study amounted to about $60 \%$ of the gross electricity generation of renewables in Germany, which was slightly lower than that of the overall generation. Therefore, the study can be considered to draw conservative rather than optimistic results regarding the EFs. The study did not consider the import and the export of the electricity between the neighboring countries.

\subsection{Data sources for emission}

The LCI datasets for each energy source from ecoinvent v3.1 were used to quantify the hourly EF of electricity (Weidema et al. 2013), and the global warming potential (GWP) based on IPCC (2013) was calculated via SimaPro (PRé Consultants 2015). The LCIA was based on a cradle-to-factory gate system boundary. The LCI datasets of electricity from ecoinvent and calculated LCIA is shown in Table 2.

For the electricity from nuclear energy, hourly generation data from EEX was only available as an aggregated value comprising data from pressurized water reactors (PWR) and boiling water reactors (BWR). Thus, the ratio of annual generation volume of PWR (78\%) and BWR (21\%) (Deutsches Atomforum e. V. 2015) was applied to quantify the hourly emission from nuclear energy. For the electricity classified in the "Other" category, the study chose biogas based on the description from EEX which mentioned the biomass as part of the category, while the category "Biomass" was represented by state-of-the-art biomass LCI dataset.

\subsection{Emission factors in various resolutions}

Since the share of energy source may vary in the electricity grid with the increased capacity of vRES, the study 
Table 1 Gross electricity generation in Germany and rate of representation in the EEX market data from 2011 to 2015

\begin{tabular}{|c|c|c|c|c|c|}
\hline & \multicolumn{2}{|c|}{ Annual generation } & \multicolumn{3}{|c|}{ Generation from renewables } \\
\hline & TWh & $\begin{array}{l}\text { Covered rate in the study } \\
\text { from EEX data }(\%)\end{array}$ & $\mathrm{TWh}$ & $\begin{array}{l}\text { Share of renewable in } \\
\text { the grid mix }(\%)\end{array}$ & $\begin{array}{l}\text { Covered rate in the study } \\
\text { from EEX data }(\%)\end{array}$ \\
\hline 2011 & 613 & 65.19 & 137 & 22.35 & 63.85 \\
\hline 2012 & 630 & 63.44 & 144 & 22.84 & 60.78 \\
\hline 2013 & 639 & 65.17 & 152 & 23.86 & 59.38 \\
\hline 2014 & 628 & 66.90 & 163 & 25.88 & 62.70 \\
\hline 2015 & 652 & 74.05 & 196 & 30.04 & 67.65 \\
\hline
\end{tabular}

investigated the variation of the EF in several time resolutions. In the study, carbon EFs were calculated as Eq. (1).

$E F_{t}=\frac{\sum G W P_{t}}{\sum G_{t}}$

where $E F$ represents the carbon $E F, G W P$ represents the emitted global warming potential from the entire electricity grid, and $G$ represents the total electricity generation of the grid at a given time $t$. The highest resolution of time $t$ was hourly.

The EFs were clustered based on three aspects: the length of the time period, the time of day, and the day of the week. Each of the clustered EF was calculated based on Eq. (1). Thus, rather than averaging the hourly EF over the respective period, the clustered EF represents corresponding emission and generation that took place during the represented period. Regarding the length of the time period, the study calculated EF for annual, monthly, and hourly resolution. The influence of the time of day was isolated by defining "daytime" and "nighttime". For the study, 6:00-18:00 was defined as the "daytime", while the rest of the hours were regarded as "nighttime". The EF of weekdays (Monday to Friday) and weekends (Saturday and Sunday) were also calculated with Eq. (1). Thus, the study investigated the potential deviation of clustered average EFs from the annual average to assess the accuracy of quantifying the emission using annual average EFs.

In order to consider the electricity measures from the consumer perspective, the losses that occurred in the grid were included. In ecoinvent, the losses along the transmission and infrastructure for the grid were accounted for in the transformation from high voltage to low voltage. The transmission loss was considered to be $2.6 \%$ for the German data. The difference between the high voltage and low voltage electricity mix for German electricity EF was $2.7 \%$, which demonstrates the limited relevance of grid infrastructure compared to the losses occurring in the grid. According to the World Bank

Table 2 Energy sources for German electricity grid mix and GWP of each LCI

\begin{tabular}{|c|c|c|}
\hline $\begin{array}{l}\text { Energy source in } \\
\text { EEX }\end{array}$ & LCI in ecoinvent & $\begin{array}{l}\mathrm{GWP} \\
{\left[\mathrm{gCO}_{2} \mathrm{eq} /\right.} \\
\mathrm{kWh}]\end{array}$ \\
\hline Coal & Electricity, high voltage $\{\mathrm{DE}\} \mid$ electricity production, hard coal $\mid$ Alloc Def, $U$ & 1112.06 \\
\hline Coal derived gas & Electricity, high voltage $\{\mathrm{DE}\} \mid$ electricity production, hard coal $\mid$ Alloc Def, $U$ & 1112.06 \\
\hline Gas & Electricity, high voltage $\{\mathrm{DE}\} \mid$ electricity production, natural gas, at conventional power plant $\mid$ Alloc Def, U & 588.52 \\
\hline Lignite & Electricity, high voltage $\{\mathrm{DE}\} \mid$ electricity production, lignite $\mid$ Alloc Def, $U$ & 1234.70 \\
\hline Oil & Electricity, high voltage $\{\mathrm{DE}\} \mid$ electricity production, oil $\mid$ Alloc Def, $U$ & 1150.68 \\
\hline Pumped-storage & Electricity, high voltage $\{\mathrm{DE}\} \mid$ electricity production, hydro, pumped storage $\mid$ Alloc Def, $U$ & 951.52 \\
\hline Run-of-the-river & Electricity, high voltage $\{\mathrm{DE}\} \mid$ electricity production, hydro, run-of-river $\mid$ Alloc Def, $U$ & 4.50 \\
\hline Seasonal-store & Electricity, high voltage $\{\mathrm{DE}\} \mid$ electricity production, hydro, reservoir, non-alpine region $\mid$ Alloc Def, $U$ & 14.37 \\
\hline Nuclear & $\begin{array}{l}\text { Electricity, high voltage }\{\mathrm{DE}\} \mid \text { electricity production, nuclear, boiling water reactor } \mid \text { Alloc Def, U; Electricity, high } \\
\text { voltage }\{\mathrm{DE}\} \mid \text { electricity production, nuclear, pressure water reactor } \mid \text { Alloc Def, } U\end{array}$ & 13.75 \\
\hline Other & Electricity, high voltage $\{\mathrm{DE}\} \mid$ heat and power co-generation, biogas, gas engine $\mid$ Alloc Def, $U$ & 313.08 \\
\hline Garbage & Electricity, high voltage $\{\mathrm{DE}\} \mid$ treatment of blast furnace gas, in power plant $\mid$ Alloc Def, $U$ & 819.47 \\
\hline Biomass & $\begin{array}{l}\text { Electricity, high voltage }\{\mathrm{DE}\} \mid \text { heat and power co-generation, wood chips, } 6667 \mathrm{~kW} \text {, state-of-the-art } 2014 \mid \text { Alloc Def, } \\
\text { U }\end{array}$ & 38.80 \\
\hline PV & $\begin{array}{l}\text { Electricity, low voltage }\{\mathrm{DE}\} \mid \text { electricity production, photovoltaic, } 3 \mathrm{kWp} \text { slanted-roof installation, single-Si, panel, } \\
\text { mounted | Alloc Def, } U\end{array}$ & 93.25 \\
\hline Wind & Electricity, high voltage $\{\mathrm{DE}\} \mid$ electricity production, wind, $>3 \mathrm{MW}$ turbine, onshore $\mid$ Alloc Def, U & 32.98 \\
\hline Offshore wind & Electricity, high voltage $\{\mathrm{DE}\} \mid$ electricity production, wind, $1-3 \mathrm{MW}$ turbine, offshore $\mid$ Alloc Def, U & 17.09 \\
\hline
\end{tabular}


Table 3 Annual average EF, minimum and maximum hourly EF of each year for German electricity grid mix for 2011 to 2015 in $\mathrm{gCO}_{2 \mathrm{eq}} / \mathrm{kWh}$. Minimum and maximum EF are recorded in $\mathrm{gCO}_{2 \mathrm{eq}} / \mathrm{kWh}$ and normalized values that take the annual average $\mathrm{EF}$ of respective year as the reference

\begin{tabular}{|c|c|c|c|c|c|c|c|c|c|c|}
\hline \multirow{2}{*}{$\frac{\text { Year }}{\text { Annual average EF }}$} & \multicolumn{2}{|l|}{2011} & \multicolumn{2}{|l|}{2012} & \multicolumn{2}{|c|}{2013} & \multicolumn{2}{|c|}{2014} & \multicolumn{2}{|c|}{2015} \\
\hline & 675 & $100 \%$ & 686 & $100 \%$ & 708 & $100 \%$ & 681 & $100 \%$ & 676 & $100 \%$ \\
\hline Min hourly EF & 328 & $49 \%$ & 351 & $51 \%$ & 278 & $39 \%$ & 250 & $37 \%$ & 278 & $41 \%$ \\
\hline Max hourly EF & 928 & $138 \%$ & 920 & $135 \%$ & 980 & $138 \%$ & 901 & $133 \%$ & 951 & $141 \%$ \\
\hline
\end{tabular}

(World Bank 2016), the losses along the transmission and distribution grid in Germany from 2011 to 2013 totaled around $4.0 \%$. In this study, the transmission loss of $4 \%$ was homogeneously applied to all energy sources for all of the investigated years when computing the EF.

\section{Results and discussion of averaged emission factors}

\subsection{Analysis of annual average and hourly emission factors}

With the data obtained from EEX and the use of Eq. (1), the hourly EF of 2011 to 2015 was derived. The annual average $\mathrm{EF}$ for each year was also calculated, and is displayed in Table 3. The table also includes the minimum and maximum hourly EF of each year, which is presented in both absolute value and normalized value based on the annual average $\mathrm{EF}$ of each respective year. In Fig. 1, the share of energy sources at the time when the minimum and maximum hourly EF occurred is depicted.

For the minimum hourly EF, the share of the vRES steadily increased each year from $43 \%$ in 2011 to $65 \%$ in 2015 .
Nevertheless, over the five investigated years, the lowest hourly EF took place in 2014 instead of 2015, although 2015 experienced the highest annual share of vRES. Moreover, the minimum hourly EF of 2015 was marginally higher than that of 2013, where 2015 had 9\% less share of vRES. This was due to the increased share of coal and gas, with the reduction of nuclear power. However, since the data from EEX does not cover the entire generation volume in Germany, further study may be necessary for a higher accuracy and precision. Yet, the result demonstrated that the variation of the hourly EF over the years can deviate substantially from the annual average EF.

\subsection{Monthly emission factors}

Figure 2 illustrates the monthly average $\mathrm{EF}$ and the share of renewable energy in the grid from 2011 to 2015 . Although the monthly average EF within a year fluctuated by nearly $30 \%$ between the minimum and maximum value, the month of the year appears not to be a reliable indication for a high or low EF. For instance, a relatively high monthly average EF was recorded during February 2012, 2013, and 2015, while this result was absent in 2011 and 2014. For the minimum monthly
Fig. 1 The share of energy sources at the time when the minimum and maximum hourly EF took place in 2011 to 2015
Fig. 2 Monthly average EF and the monthly average share of renewable energy in the German electricity grid mix for 2011 to 2015
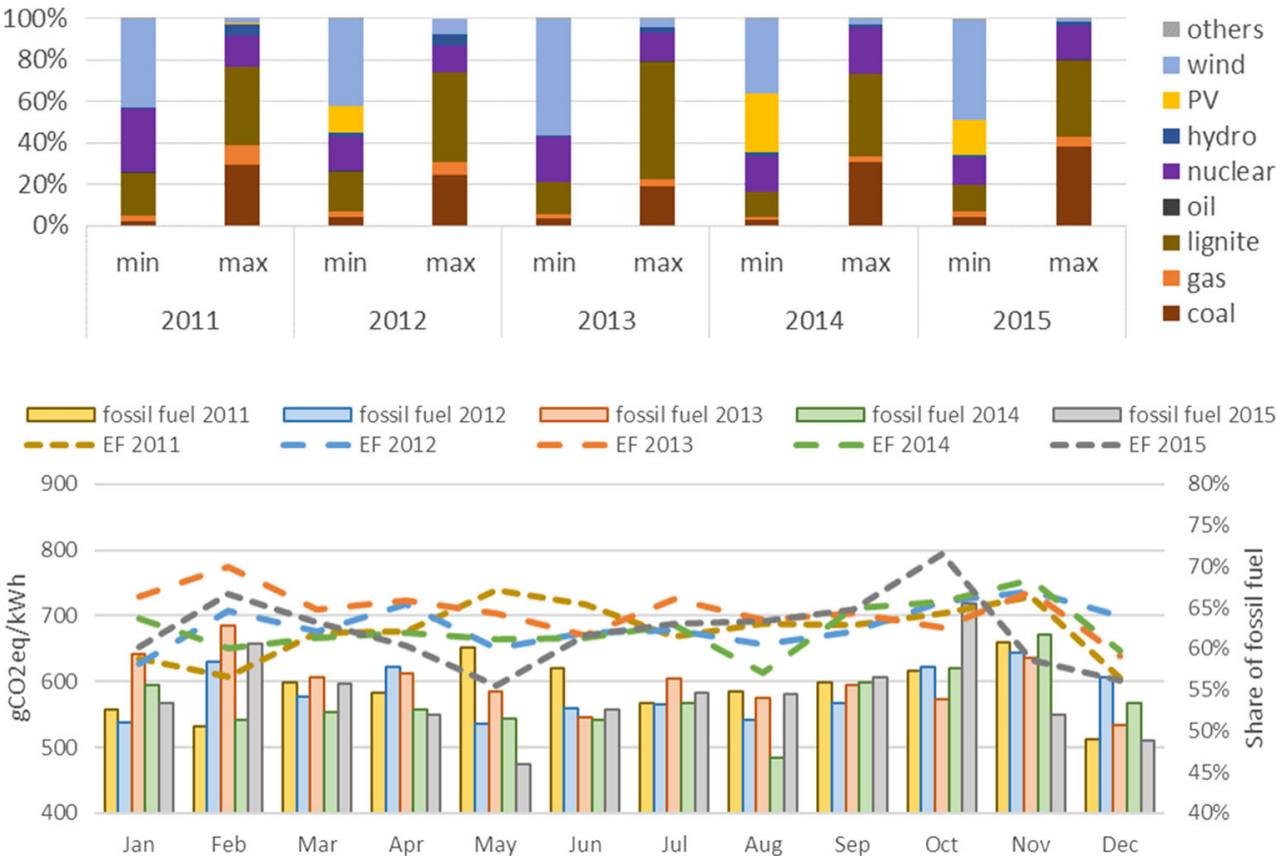
Table 4 Annual average EFs subdivided into weekdays and weekends from 2011 to 2015. Annual average EF of each year was taken as a reference

\begin{tabular}{|c|c|c|c|c|c|c|c|c|c|c|}
\hline Year & 2011 & & 2012 & & 2013 & & 2014 & & 2015 & \\
\hline Unit & {$\left[\mathrm{gCO}_{2 \mathrm{eq}} / \mathrm{kWh}\right]$} & $(\%)$ & {$\left[\mathrm{gCO}_{2 \mathrm{eq}} / \mathrm{kWh}\right]$} & $(\%)$ & {$\left[\mathrm{gCO}_{2 \mathrm{eq}} / \mathrm{kWh}\right]$} & $(\%)$ & {$\left[\mathrm{gCO}_{2 \mathrm{eq}} / \mathrm{kWh}\right]$} & $(\%)$ & {$\left[\mathrm{gCO}_{2 \mathrm{eq}} / \mathrm{kWh}\right]$} & $(\%)$ \\
\hline Weekly & 675 & 100 & 686 & 100 & 708 & 100 & 681 & 100 & 676 & 100 \\
\hline Weekday & 689 & 102 & 699 & 102 & 725 & 103 & 701 & 103 & 697 & 103 \\
\hline Weekend & 635 & 94 & 647 & 94 & 656 & 93 & 623 & 91 & 615 & 91 \\
\hline
\end{tabular}

average EF, January was the lowest in 2012, while December was the lowest in 2011 and 2013. In 2014, August was the lowest, and May in 2015 which were in completely different seasons of the year compared to the former 3 years.

However, the deviation of the monthly average EF between the best and the worst month over the years tended to increase. In 2012, the difference of monthly average EF between January and November was $17 \%$ against the annual average EF. The difference between the best and worst monthly average EF increased to $20 \%$ in $2013,21 \%$ in 2014 , and $31 \%$ in 2015. These results indicated that with the increased share of renewable energy, in which vRES was the major contributor, the consideration of the month of electricity consumption becomes more important to the accuracy of quantifying the emission.

\subsection{Difference between weekdays and weekends}

In order to investigate the influence of the time of consumption from a different viewpoint, the relevance of the day of the week was studied. Table 4 illustrates the annual average EF, clustered based on the day of a week. In Fig. 3, the share of energy sources and the average daily volume of electricity generation for weekdays and weekends are presented.

The result showed that the annual average EF of the weekend was becoming "cleaner" than the overall average, by having a lower proportion of fossil fuel in the grid mix with a lower volume of generated electricity than the weekday. It is therefore clear that electricity consumed on the weekends was cleaner than the emission calculated using the annual average EF for the last 5 years. The finding suggests the overestimation of the quantified GHG emission of the weekend by nearly $10 \%$ when the annual average EF is used.
In Table 5, the monthly average EF subdivided into weekdays and weekends is presented from 2011 to 2015 . The values were normalized by the annual average EF of each year.

The results revealed the increasing deviation of some cleaner monthly average EF of the weekend against the annual average EF over the years. In addition to the values from the weekend, some of the "dirtier" monthly average EF of the weekdays also experienced a greater deviation from the annual average EF. It is therefore possible that an increasing variation of the "cleanliness" of the grid mix depends on the day of the week and increased share of vRES. With some months experiencing a nearly $20 \%$ underestimation on weekdays and $25 \%$ of overestimation on weekends, the use of annual average EF for consumers with specific consumption patterns on the day of the week may be considered as inappropriate.

\subsection{Difference between the daytime and nighttime}

The last scope of investigation in relation to the time of consumption was the time of day. In Table 6, the annual average EF was clustered based on the time of day and the day of the week, which were normalized by the annual average EF. In Fig. 4, the share of energy sources and the average daily volume of electricity generation were clustered into four groups of daytimes and nighttimes of weekdays and weekends.

Demonstrably, the electricity user who consumes only during the daytime on the weekend would have their GHG emission overestimated by nearly $15 \%$ when the annual average EF was used to calculate the emissions in 2013 to 2015. This overestimation was due to the increased proportion of nonfossil fuel in the energy mix of the electricity through increased available volume of such energy sources, especially from both vRES. While the decrease of the total volume of
Fig. 3 Share of energy sources and average daily electricity generation volume for weekdays and weekends from 2011 to 2015

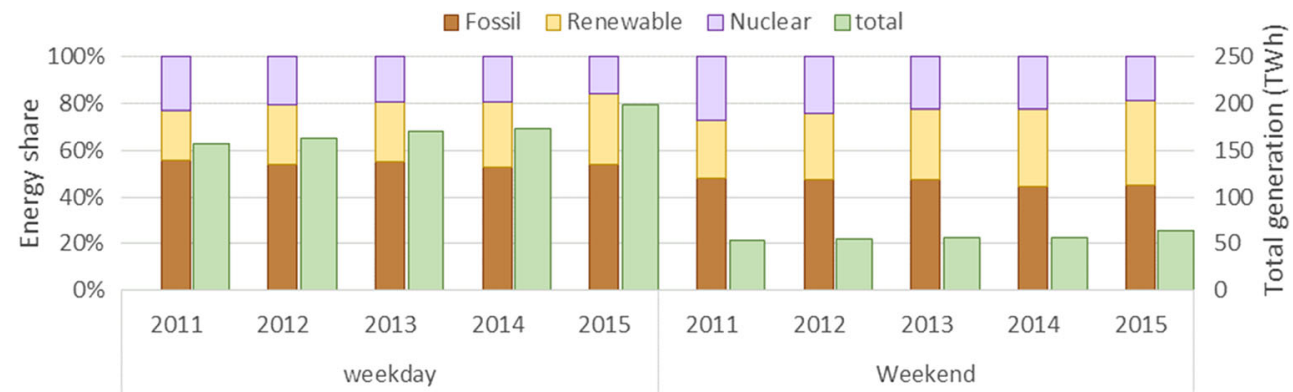


Table 5 Monthly average EF clustered based on day of the week, normalized by annual average EF

\begin{tabular}{|c|c|c|c|c|c|c|c|c|c|c|c|c|c|}
\hline & & $\operatorname{Jan}(\%)$ & Feb $(\%)$ & $\operatorname{Mar}(\%)$ & $\operatorname{Apr}(\%)$ & May (\%) & Jun $(\%)$ & Jul (\%) & Aug (\%) & Sep $(\%)$ & Oct $(\%)$ & Nov $(\%)$ & $\operatorname{Dec}(\%)$ \\
\hline \multirow[t]{3}{*}{2011} & Weekly & $94.00 * *$ & $90.10 * *$ & 100.00 & 100.30 & $109.40^{*}$ & $106.20^{*}$ & 98.90 & 102.00 & 101.70 & 104.20 & $108.10^{*}$ & $89.80 * *$ \\
\hline & Weekday & 97.70 & $93.30 * *$ & 100.40 & 101.50 & $*$ & $0 *$ & 103.80 & 102.70 & 101.80 & 104.10 & $0 *$ & $91.60 * *$ \\
\hline & Weekend & $85.40^{* *}$ & $80.90 * *$ & 98.70 & 96.90 & 100.40 & 97.80 & $87.40 * *$ & 99.50 & 101.50 & 104.20 & 99.50 & $70 * *$ \\
\hline \multirow[t]{3}{*}{2012} & Weekly & $91.60 * *$ & 103.10 & 98.70 & 104.60 & $94.80 * *$ & 98.30 & 98.80 & 95.80 & 98.60 & $105.30 *$ & $107.60 *$ & 102.00 \\
\hline & Weekday & $92.80 * *$ & 103.60 & 101.90 & $107.70 *$ & 96.40 & 102.20 & 100.80 & 98.10 & 100.10 & $106.80 *$ & $108.70 *$ & 104.20 \\
\hline & Weekend & $87.90 * *$ & 101.90 & $89.10 * *$ & 95.80 & $89.40 * *$ & $87.90 * *$ & $93.00 * *$ & $88.30 * *$ & 95.00 & 100.20 & 104.10 & 97.00 \\
\hline \multirow[t]{3}{*}{2013} & Weekly & 103.10 & $109.50 *$ & 100.20 & 102.10 & 99.40 & $94.70 * *$ & 102.50 & 98.10 & 99.50 & 96.40 & 104.10 & $90.40 * *$ \\
\hline & Weekday & 103.10 & $110.10 *$ & $105.30 *$ & 102.90 & 102.10 & 100.90 & 104.90 & 101.60 & 101.70 & 97.50 & $106.70 *$ & $93.60 * *$ \\
\hline & Weekend & 103.10 & $107.90 *$ & $88.00 * *$ & 99.60 & $90.20 * *$ & $79.00 * *$ & $94.20 * *$ & $88.30 * *$ & $93.50 * *$ & $92.40 * *$ & 97.40 & $81.60 * *$ \\
\hline \multirow[t]{3}{*}{2014} & Weekly & 102.30 & 95.70 & 97.90 & 98.90 & 97.70 & 98.00 & 100.60 & $90.00 * *$ & 104.70 & $106.00 *$ & $110.90 *$ & 95.10 \\
\hline & Weekday & 105.00 & 101.40 & 102.00 & 100.90 & 100.70 & 100.60 & 102.50 & $93.90 * *$ & $105.40^{*}$ & $108.50 *$ & $115.20 *$ & 96.40 \\
\hline & Weekend & $93.40 * *$ & $79.90 * *$ & $87.90 * *$ & $92.40 * *$ & $88.90 * *$ & $90.80 * *$ & $94.30 * *$ & 80.70 ** & 102.30 & 97.10 & 100.40 & $91.00 * *$ \\
\hline \multirow[t]{3}{*}{2015} & Weekly & 96.30 & $108.40 *$ & 101.90 & 96.70 & $87.90 * *$ & 99.10 & 101.80 & 102.40 & 104.90 & $117.40 *$ & $93.60 * *$ & $88.80 * *$ \\
\hline & Weekday & 99.00 & $112.20 *$ & 104.10 & 98.70 & $92.50 * *$ & 101.90 & 103.40 & 105.00 & $108.00^{*}$ & $119.00 *$ & 97.70 & $93.70 * *$ \\
\hline & Weekend & $88.90 * *$ & 97.30 & 95.30 & $89.80 * *$ & $76.20 * *$ & $89.50 * *$ & 96.50 & 95.60 & $94.70 * *$ & $112.80 *$ & $82.70 * *$ & $73.30 * *$ \\
\hline
\end{tabular}

*The values higher than $105 \%$

$* *$ The values lower than $95 \%$

Table 6 Normalized annual average EF of the time of a day and the day of the week for 2011 to 2015

\begin{tabular}{|c|c|c|c|c|c|c|c|c|c|c|}
\hline & \multicolumn{2}{|l|}{2011} & \multicolumn{2}{|l|}{2012} & \multicolumn{2}{|l|}{2013} & \multicolumn{2}{|l|}{2014} & \multicolumn{2}{|l|}{2015} \\
\hline & Day (\%) & Night (\%) & Day (\%) & Night (\%) & Day (\%) & Night (\%) & Day (\%) & Night (\%) & Day (\%) & Night (\%) \\
\hline Weekly & 98.2 & 102.1 & 96.2 & 104.6 & 95.8 & 105.0 & 95.5 & 105.5 & 96.0 & 104.8 \\
\hline Weekday & 100.8 & 103.7 & 98.8 & 105.9 & 98.8 & 107.0 & 98.9 & 107.8 & 99.4 & 107.4 \\
\hline Weekend & 90.5 & 97.9 & 88.5 & 101.0 & 86.8 & 99.4 & 84.9 & 99.1 & 85.3 & 97.3 \\
\hline
\end{tabular}

produced electricity more significantly affected the proportion of the non-fossil fuel between weekdays and weekends, the increase of volume of non-fossil fuel energy sources exerted more influence in the daytime than the nighttime. On the weekend, the difference in generated electricity volume between the daytime and nighttime over the year was around $5 \%$, whereas the difference in the share of fossil fuel in the mix was nearly $10 \%$. Thus, the inaccuracy of using the annual average EF to calculate the emission of daytime electricity consumers on weekends in a grid where the share of vRES, mainly from solar energy, is expected to increase.

On the other hand, the individuals who consumed electricity during the nighttime on weekdays experienced emission underestimation of nearly $7 \%$ when calculating emissions through
Fig. 4 Share of energy sources and average daily electricity generation volume for the daytime and the nighttime of weekdays and weekends from 2011 to 2015

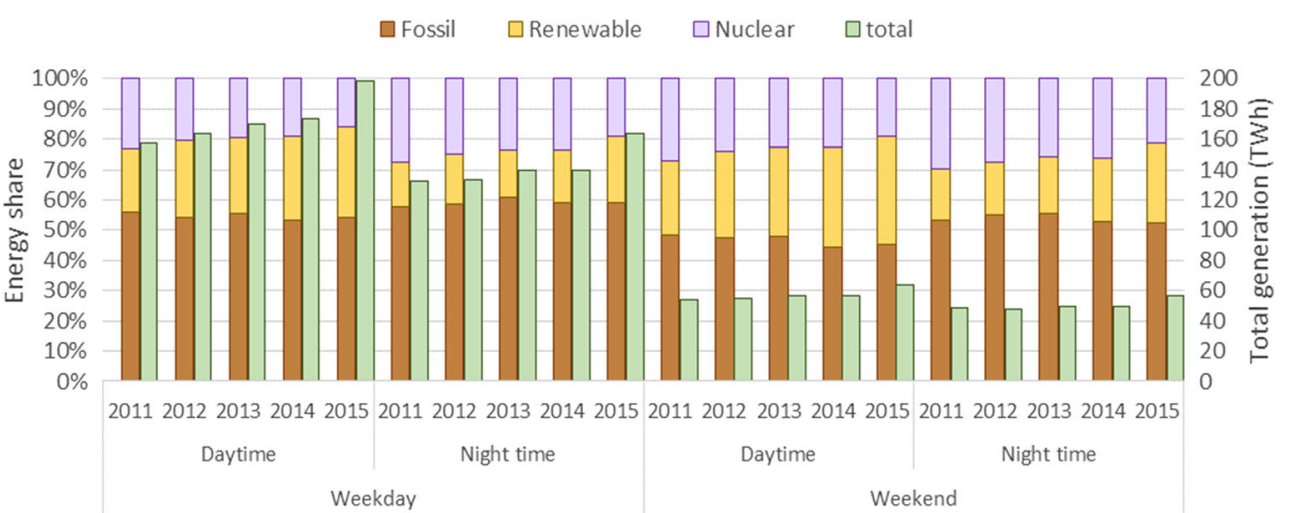


Table 7 Monthly EF clustered in weekday, weekend, daytime and nighttime normalized by annual EF for 2011 to 2015 $\begin{array}{lllllllllll}\text { Jan }(\%) & \text { Feb (\%) } & \text { Mar (\%) } & \text { Apr (\%) } & \text { May (\%) Jun (\%) } & \text { Jul (\%) } & \text { Aug (\%) } & \text { Sep (\%) } & \text { Oct (\%) } & \text { Nov (\%) } & \text { Dec (\%) }\end{array}$

\begin{tabular}{|c|c|c|c|c|c|c|c|c|c|c|c|c|c|c|}
\hline \multirow[t]{9}{*}{2011} & \multirow[t]{3}{*}{ Weekly } & aily & $.00 * *$ & $0.10 * *$ & 0.00 & 0.30 & $109.40 *$ & $106.20 *$ & 98.90 & 102.00 & 101.70 & 104.20 & $08.10^{*}$ & $9.80^{*}$ \\
\hline & & Day & 95.80 & $1.00 * *$ & 7.70 & 0 & 10 & 10 & 10 & 70 & .20 & 50 & )* & $30 * *$ \\
\hline & & it & $*$ & * & 60 & 0 & * & $10 *$ & .50 & $.10 *$ & $6.00 *$ & $10^{*}$ & $0 *$ & $00 *$ \\
\hline & \multirow[t]{3}{*}{ Weekday } & Daily & 7.70 & 3.3 & 0.40 & 50 & 11 & $108.90 *$ & 103.80 & 102.70 & 01.80 & 104.10 & $1.00 *$ & $.60 *$ \\
\hline & & Day & 95.80 & 1.0 & 97.70 & 96.40 & 10 & 102.20 & 95.10 & 97.70 & 98.20 & 102.50 & $8.50 *$ & $30 *$ \\
\hline & & Night & $4.60 * *$ & $1.60 * *$ & 102.40 & $05.50 *$ & $119.30 *$ & $113.00^{*}$ & $108.20^{*}$ & $107.50^{*}$ & $105.70 *$ & $105.20 *$ & $10.20 *$ & 30 * \\
\hline & \multirow[t]{3}{*}{ Weekend } & Daily & $85.40 * *$ & $80.90 * *$ & 98.70 & 96.90 & 100.40 & 97.80 & $87.40 * *$ & 99.50 & 101.50 & 104.20 & 50 & $4.70 * *$ \\
\hline & & Day & $84.50 * *$ & $79.90 * *$ & $94.60 * *$ & $91.20 * *$ & $92.70 * *$ & $91.70 * *$ & $82.40 * *$ & $93.90 * *$ & 97.00 & 100.60 & 40 & $70 *$ \\
\hline & & Night & $6.20 * *$ & $82.00 * *$ & 103.10 & 03.40 & 109 & 105.00 & $93.10 * *$ & $105.90 *$ & $106.70 *$ & $30 *$ & 70 & $60 * *$ \\
\hline \multirow[t]{9}{*}{2012} & \multirow[t]{3}{*}{ Weekly } & Daily & $1.60 * *$ & 10 & 98.70 & 60 & & 98.30 & 98.80 & 95.80 & & & $50 *$ & .00 \\
\hline & & Day & $92.30 * *$ & 102.00 & 94.5 & 99.00 & 87. & 91.5 & $91.40 * *$ & $88.80 * *$ & 92.6 & 10 & D* & .80 \\
\hline & & Night & ** & 104.40 & 103 & 0* & 10 & 10 & 10 & 104.80 & 10 & 0* & )* & .20 \\
\hline & \multirow[t]{3}{*}{ Weekday } & Daily & $92.80 * *$ & 103.60 & 101.90 & $.70 *$ & 96.40 & 10 & 100.80 & 98.10 & 100.10 & $80 *$ & $.70 *$ & 4.20 \\
\hline & & Day & $92.30 * *$ & 102.00 & $94.50 * *$ & 99.00 & 87.7 & $91.50 * *$ & $91.40 * *$ & 88.80 ** & $92.60 * *$ & 102.60 & $108.10^{*}$ & 2.80 \\
\hline & & Night & $91.10 * *$ & 103.90 & $106.50 *$ & $113.80 *$ & $105.60 *$ & $109.90 *$ & $110.20^{*}$ & $106.40^{*}$ & $106.60 *$ & $109.50 *$ & $08.00^{*}$ & 2.60 \\
\hline & \multirow[t]{3}{*}{ Weekend } & Daily & $87.90 * *$ & 101.90 & $89.10 * *$ & 95.80 & 89. & $87.90 * *$ & $93.00 * *$ & 88.30 ** & 95.00 & 20 & 10 & .00 \\
\hline & & Day & 86.2 & 98.30 & 83. & 87.9 & 81. & 77.9 & 83. & $79.00 * *$ & 86. & 9 & & 20 \\
\hline & & Night & ** & 105 & 9 & $0 *$ & 100 & 80 & 10 & 99 & 90 & & 20 & .90 \\
\hline \multirow[t]{9}{*}{2013} & \multirow[t]{3}{*}{ Weekly } & Daily & 03.10 & 109 & 100.20 & 2.10 & 99. & 9 & 50 & 98.10 & 99.50 & 9 & 0 & 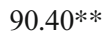 \\
\hline & & Day & 1 & 108 & 5.90 & 5.50 & 92 & 87. & 9 & 89.9 & *** & $94.40 * *$ & 80 & 20 \\
\hline & & Night & 0 & 11 & * & $0 *$ & 10 & 0 & 1 & 10 & 10 & 98.70 & & 0.0 \\
\hline & \multirow[t]{3}{*}{ Weekday } & Daily & 1 & 11 & 1 & 0 & 1 & 0 & 1 & 0 & 0 & 9 & $70^{*}$ & 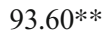 \\
\hline & & Day & 103 & 108 & 95.90 & 95.50 & 92 & 87 & 9 & 89.9 & 94. & *** & 1 & $0 * *$ \\
\hline & & $\mathrm{N}$ & 0 & 11 & * & $0 *$ & 10 & 1 & 1 & * & * & 99.70 & D* & $0 * *$ \\
\hline & \multirow[t]{3}{*}{ Weekend } & Daily & 1 & 10 & * & 9 & $*$ & 7 & ** & $* *$ & ** & & & $0 * *$ \\
\hline & & Day & 02.60 & * & * & * & & & $* *$ & ** & & & & \\
\hline & & Night & 03.70 & * & & 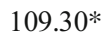 & & & & & & & & $60 * *$ \\
\hline \multirow[t]{9}{*}{2014} & \multirow[t]{3}{*}{ Weekly } & Daily & 30 & 9 & & & & & & & & & & 95.10 \\
\hline & & Day & 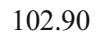 & 9 & $* *$ & $20^{* *}$ & 8 & $* *$ & 9 & $0 * *$ & 99.00 & & & \\
\hline & & Night & .70 & 97.60 & 60 & $80 *$ & $108.80 *$ & $111.20^{*}$ & $112.40^{*}$ & 101.20 & $111.80^{*}$ & $108.40 *$ & $10.50 *$ & 1.00 \\
\hline & \multirow[t]{3}{*}{ Weekday } & Daily & 5.00 & 101.40 & .00 & 0.90 & 100.70 & 100.60 & 102.50 & $93.90 * *$ & $105.40 *$ & $108.50 *$ & $115.20 *$ & 96.40 \\
\hline & & Day & 102.90 & $93.90 * *$ & $92.30 * *$ & $1.20 * *$ & 89.30 ** & $88.20 * *$ & $91.80 * *$ & $81.60 * *$ & 99.00 & & $11.20 *$ & 96.00 \\
\hline & & Night & 04.70 & 102.10 & $08.50^{*}$ & $110.00 *$ & $110.50 *$ & $112.90 *$ & $113.40^{*}$ & 104.20 & $111.70^{*}$ & $110.40 *$ & $14.00 *$ & 95.50 \\
\hline & \multirow[t]{3}{*}{ Weekend } & Daily & $93.40 * *$ & $79.90 * *$ & $87.90 * *$ & $92.40 * *$ & $88.90 * *$ & $90.80 * *$ & $94.30 * *$ & $80.70 * *$ & 102.30 & 97.10 & 100.40 & $91.00 *$ \\
\hline & & Day & $94.60 * *$ & $74.70 * *$ & $81.20 * *$ & $82.00 * *$ & $77.40 * *$ & $78.40 * *$ & $82.70 * *$ & $70.00 * *$ & $93.90 * *$ & $93.00 * *$ & 98.40 & $92.20 *$ \\
\hline & & Night & $2.30 * *$ & $85.70 * *$ & 95.40 & 05.00 & 103.80 & $106.70 *$ & 109.10 * & $94.40 * *$ & $112.20^{*}$ & 101.70 & 102.50 & $89.80 *$ \\
\hline \multirow[t]{9}{*}{2015} & \multirow[t]{3}{*}{ Weekly } & Daily & 96.30 & $108.40^{*}$ & 101.90 & 96.70 & $87.90 * *$ & 99.10 & 101.80 & 102.40 & 104.90 & $117.40 *$ & $93.60 * *$ & $88.80 *$ \\
\hline & & Day & 96.50 & $106.70^{*}$ & 97.70 & $88.50 * *$ & $80.70 * *$ & $92.20 * *$ & $93.00 * *$ & $94.80 * *$ & 100.30 & 114.30 & $94.90 * *$ & $90.30 *$ \\
\hline & & Night & 96.20 & $110.20 *$ & $106.90 *$ & $106.90 *$ & 97.20 & $108.10^{*}$ & $113.00^{*}$ & $111.70^{*}$ & $110.40^{*}$ & $120.90 *$ & $92.30 * *$ & $87.20 *$ \\
\hline & \multirow[t]{3}{*}{ Weekday } & Daily & 99.00 & $112.20 *$ & 104.10 & 98.70 & $92.50 * *$ & 101.90 & 103.40 & 105.00 & $108.00 *$ & $119.00 * *$ & 97.70 & $93.70 * *$ \\
\hline & & Day & 96.50 & $106.70^{*}$ & 97.70 & $88.50 * *$ & $80.70 * *$ & $92.20 * *$ & $93.00 * *$ & $94.80 * *$ & 100.30 & $114.30 *$ & $94.90 * *$ & $90.30 *$ \\
\hline & & Night & 98.40 & $114.10 *$ & $109.40^{*}$ & $108.60 *$ & 101.00 & $110.10^{*}$ & $114.00^{*}$ & $113.00^{*}$ & $112.70^{*}$ & $122.00 *$ & 96.40 & 91.20 ** \\
\hline & Weekend & Daily & $88.90 * *$ & 97.30 & 95.30 & $89.80 * *$ & $76.20 * *$ & $89.50 * *$ & 96.50 & 95.60 & $94.70 * *$ & $112.80 *$ & $82.70 * *$ & $73.30 * *$ \\
\hline & & Day & $87.70 * *$ & 95.30 & $91.30 * *$ & $80.30 * *$ & $66.60 * *$ & $79.40 * *$ & $85.50 * *$ & $84.70 * *$ & $87.30 * *$ & $108.10 *$ & $83.70 * *$ & $71.70 * *$ \\
\hline & & Night & $90.20 * *$ & 99.40 & 99.60 & 101.00 & $87.90 * *$ & 101.40 & $109.40 *$ & $108.50 *$ & 103.10 & $117.80^{*}$ & $81.70 * *$ & 75.10 ** \\
\hline
\end{tabular}

*The values higher than $105 \%$

**The values lower than $95 \%$ 
Fig. 5 Difference between maximum and minimum monthly average EF for each cluster of time resolution for 2011 to 2015

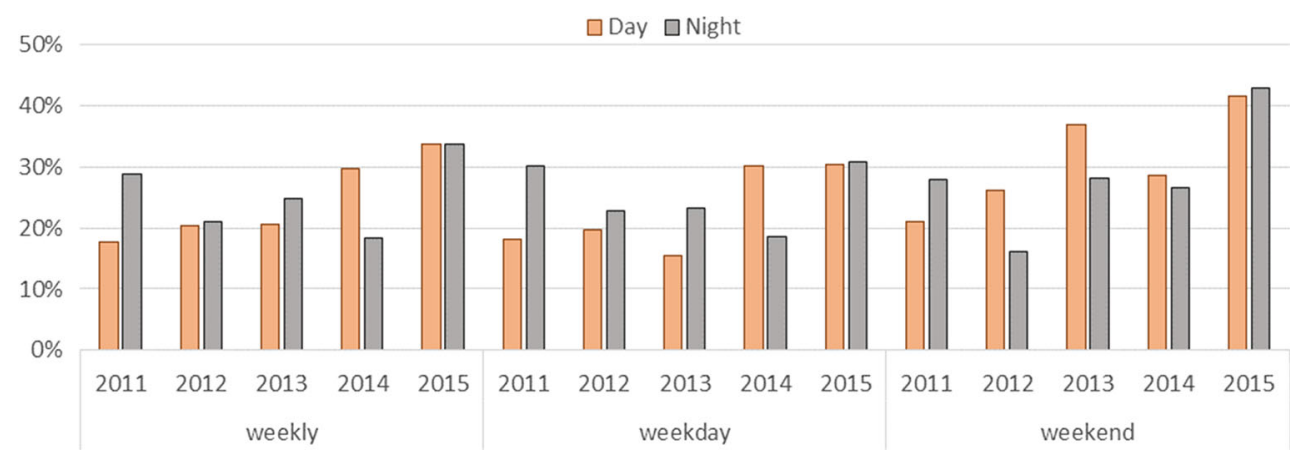

annual average EF in 2012 to 2015. The decreased share of renewable energy, primarily from solar, in the grid mix clearly affected the "cleanliness" of the consumed electricity.

Table 7 depicts the results further broken down into months. In Fig. 5, the maximum differences among the monthly average EFs for each cluster are given.

The results of clustering the monthly average EF into the time of day and the day of the week depicted that the range of underestimation and overestimation varied from 22\% (2015 weekday nighttime of October) and 34\% (2015 weekend daytime of May), respectively. The result did not exhibit clear trends for specific months, as noted in Chapter 3.2. Nonetheless, from March to September, the EF of weekday daytime was generally less than the annual average EF (up to $15 \%$ ), and weekend daytime was around $20 \%$ less. Another clear tendency demonstrated in Fig. 5 was the increasing deviation of minimum and maximum monthly average $\mathrm{EF}$ for each cluster of time, especially the decrease of EF during the daytime. The increasing EF difference suggests the increasing inaccuracy of quantifying GHG emission with the annual average $\mathrm{EF}$ for electricity consumers with varying demands over the months during the daytime with the higher grid share of vRES.

\subsection{Uncertainty in the result}

The study is possibly affected by several aspects of uncertainty that might influence the obtained results. The first aspect of uncertainty was the exclusion of the import and export of electricity between the neighboring grids. According to BDEW (2016), the amount of export that took place between 2011 and 2015 was around 55 to $85 \mathrm{TWh}$, where the amount of import was around 30 to $50 \mathrm{TWh}$. While the share of export increased from 9 to $13 \%$ of the gross electricity generation for the respective years, the share of import decreased from 8 to $5 \%$. Since the inflow of electricity from neighboring grids involves its own mixes and corresponding EFs, the decreasing share of the import implies the decreasing uncertainty of the calculated EF.

Another factor of uncertainty was the sample size of the weekends of each month, which is less than 10 days in
Chapter 3.4. With such a limited sample size, the effect of extreme weather events, for instance, may play a significant role in the corresponding EF, especially for vRES.

\section{Conclusions}

In light of the recent increase of vRES in the German electricity grid, the study calculated the higher temporal resolution of the grid mix from 2011 to 2015. The study assessed the accuracy of the quantified emissions by using the annual average EF through different clusters of time. In the study, the increase of vRES, which was the main source for the increase of renewable energy as a whole, was demonstrated. This affected the variation of the "cleanliness" of hourly EF over the years. This observation suggested the increasing importance of applying the hourly EF over annual average EF with the increase of vRES in the grid for accurate quantification of emission.

Moreover, the study revealed that weekend daytime consumers may have their emissions overestimated by the annual average $\mathrm{EF}$, while the weekday nighttime consumers may have been underestimated. The difference in EF between the days of the week increased over the years. The increase of vRES may have played an important role in this increase. Furthermore, the accuracy of calculating the emission of daytime and nighttime was also affected by the increase of the vRES, where the deviation of these two EFs from the annual average EF was generally increasing. This implies the weakness of applying the annual average EF on consumers who typically use the electricity during the weekday nighttime or weekend daytime. The study also found that when the consumption volume differs from month to month, the inaccuracy of quantified emission may rise, which was evident from the monthly average EF results.

On the other hand, the weekday daytime EF recorded very similar values to the annual average EF, suggesting the appropriateness of the use of the annual average EF for quantifying the emission of the consumer who typically consumes electricity during the weekday daytime.

For future research, the influence of the increased vRES on the EFs may require further investigation. The influence may 
be investigated by taking other countries such as Denmark, Italy, or Spain - which record high levels of penetration of vRES in the grid recently (Eurostat 2016) - as a case study. However, access to hourly generation data in the grid would be a challenge. The limitation of the study regarding the coverage of generation data may also be strengthened in the future. Furthermore, the limitation regarding the exchange of electricity between the neighboring countries may influence the cleanliness of the electricity. However, in order to account for the influence of taking inflow of electricity from neighboring grids into account, the EF of the inflow electricity will need to be included in the hourly resolution. Furthermore, the inclusion of neighboring grid electricity of Germany will call for further inclusion of grids surrounding the German neighboring grids as electricity in Europe is traded on a continental scale. This calls for the further investigation of the hourly EF of other grids to allow the inclusion of electricity from other grids.

Acknowledgements The authors would like to thank the EIT Climate KIC for funding the $\mathrm{PhD}$ studies for J. Kono and Chalmers Area of Advance Built Environment as well as Energy for their support of the interdisciplinary research at Chalmers.

Open Access This article is distributed under the terms of the Creative Commons Attribution 4.0 International License (http:// creativecommons.org/licenses/by/4.0/), which permits unrestricted use, distribution, and reproduction in any medium, provided you give appropriate credit to the original author(s) and the source, provide a link to the Creative Commons license, and indicate if changes were made.

\section{References}

BDEW (2016) Erneuerbare Energien und das EEG: Zahlen, Fakten, Grafiken (2016) Anlagen, installierte Leistung, Stromerzeugung, EEG-Auszahlungen, Marktintegration der Erneuerbaren Energien und regionale Verteilung der EEG-Anlagen BDEW Bundesverband der Energie- und Wasserwirtschaft e.V., Reinhardtstraße 32, 10117 Berlin

BMU (2013) Renewable Energy Sources 2012. Federal Ministry for the Environment, Nature Conservation and Nuclear Safety (BMU) Division E I 1 (Strategic and Economic Aspects of the Energiewende)

Commission of the European Communities (2008) Package of Implementation measures for the EU's objectives on climate change and renewable energy for 2020
Cubi E, Doluweera G, Bergerson J (2015) Incorporation of electricity GHG emissions intensity variability into building environmental assessment. Appl Energy 159:62-69

Deutsches Atomforum e. V. (2015) Betriebsergebnisse Kernkraftwerke 2014. http://www.kernenergie.de/kernenergie-wAssets/docs/presse/ PM-2015-01-22_KKW-Betriebsergebnisse_2014.pdf. Accessed July 9th 2015

European Energy Exchange AG (2015) Transparency Data. European Energy Exchange AG,. European Energy Exchange AG,. http:// www.eex.com/.

Eurostat (2016) SHARES 2014 SHort Assessment of Renewable Energy Sources, February 10, 2016 edn

IPCC (2013) Climate change 2013: the physical science basis. Contribution of working group I to the fifth assessment report of the intergovernmental panel on climate change. Cambridge University Press, Cambridge and New York. doi:10.1017/ CBO9781107415324

Levasseur A, Lesage P, Margni M, Deschênes L, Samson R (2010) Considering time in LCA: dynamic LCA and its application to global warming impact assessments. Environ Sci Technol 44:3169-3174

Mendoza J-MF, Oliver-Solà J, Gabarrell X, Josa A, Rieradevall J (2012) Life cycle assessment of granite application in sidewalks. Int J Life Cycle Assess 17:580-592

Messagie $\mathrm{M}$ et al (2014) The hourly life cycle carbon footprint of electricity generation in Belgium, bringing a temporal resolution in life cycle assessment. Appl Energ 134:469-476

Morris C, Pehnt M (2015) Energy transition: the German Energiewende. Heinrich Böll Stiftung, Berlin

Paraschiv F, Erni D, Pietsch R (2014) The impact of renewable energies on EEX day-ahead electricity prices. Energ Policy 73:196-210

Pinsonnault A, Lesage P, Levasseur A, Samson R (2014) Temporal differentiation of background systems in LCA: relevance of adding temporal information in LCI databases. Int J Life Cycle Assess 19: $1843-1853$

PRé Consultants (2015) SimaPro Version 8.05. The Netherlands

Reap J, Roman F, Duncan S, Bras B (2008) A survey of unresolved problems in life cycle assessment. Int J Life Cycle Assess 13:290 300

Torrellas M, Antón A, López JC, Baeza EJ, Parra JP, Muñoz P, Montero JI (2012) LCA of a tomato crop in a multi-tunnel greenhouse in Almeria. Int J Life Cycle Assess 17:863-875

Treyer K, Bauer C (2016) Life cycle inventories of electricity generation and power supply in version 3 of the ecoinvent database - part I: electricity generation. Int J Life Cycle Assess 21:1236-1254

UNFCCC (2016) Report of the Conference of the Parties on its twentyfirst session, held in Paris from 30 November to 13 December 2015

Weidema BP, Bauer C, Hischier R et al. (2013) The ecoinvent database: Overview and methodology, Data quality guideline for the ecoinvent database version 3

World Bank (2016) World DataBank. In: Electr. power Transm. Distrib. losses (\% output). http://databank.worldbank.org/data/reports.aspx? source $=2 \&$ series $=$ EG.ELC.LOSS.ZS \& country $=$ DEU\# 